\section{TRATAMIENTO ORTOPEDICO FUNCIONAL DE UN PACIENTE CON MORDIDA CRUZADA ANTERIOR EN DENTICIÓN DECIDUA}

Jimmy Richard Gamboa Reyes, Elias Ernesto Aguirre Siancas Centro Peruano De Audición, Lenguaje y Aprendizaje

Lima-Perú

\title{
RESUMEN
}

Objetivo: Este trabajo propone presentar una alternativa de tratamiento oportuno para la mordida cruzada anterior en niños, mediante la presentación de un caso clínico tratado con Ortopedia Funcional de los Maxilares basado en los principios de la Rehabilitación Neuro- oclusal. Material y métodos: Se realizó una evaluación integral a la paciente, una niña de cinco años de edad con dentición decidua, diagnosticándosele mordida cruzada anterior. La fase de tratamiento fue realizado en dos etapas; en la primera se emplearon la Pistas Planas Directas instalándolas en los incisivos centrales superiores. En la segunda fase se utilizó aparatología ortopédica funcional siendo empleado el SN3 diseñado por Wilma Simoes. Se realizó comparación de los cambios en el maxilar, la mandíbula y el proceso dentoalveolar mediante fotografías clínica, estudio cefalométrico de Bimler y evaluación de la dinámica mandibular. Resultados: Después de diecisiete meses de tratamiento ortopédico funcional se produjo una rotación posterior de la mandíbula, crecimiento anteroposterior del maxilar, desarrollo dentoalveolar de ambas arcadas, se modificó la postura de la lengua. Se obtienen resultados importantes en la relación entre el maxilar, la mandíbula, y el plano oclusal así también se aprecian cambios significativos en el rostro y el perfil. Conclusiones: El tratamiento ortopédico funcional podría controlar el crecimiento y rotación de la mandíbula y la maxila generando cambios sagitales, verticales y dentoalveolares; favorables para la corrección de la mordida cruzada anterior y logrando así mejorar la eficiencia masticatoria y el la fisiología del sistema estomatognático.

Palabras clave: Tratamiento Oportuno, Mordida Cruzada Anterior, Ortopedia Funcional, Mandíbula, Maxila

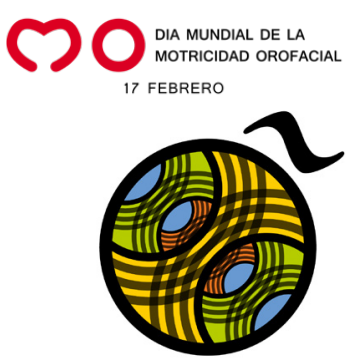

